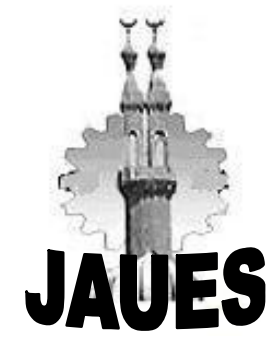

Journal of Al Azhar University Engineering Sector

Vol. 14, No. 52, July 2019, 1247-1257

\title{
THE EFFECT OF UTILIZING DYNAMIC SHADING ELEMENTS ON THERMAL PERFORMANCE IN OFFICE BUILDINGS IN EGYPT
}

\section{Hadeer Maged Mohamed Abdel Hafez}

Department of Architect Engineering, Ain Shams University hadeermaged90@gmail.com

\begin{abstract}
ABASTRACT
This research is based on two parts, one of them is theoretical and the other part is analytical. The theoretical part discusses the concept of the thermal comfort which is an integral part of the human comfort inside the office buildings, the methods of heat transfer to the inside of the building. It also discusses the effect of the design elements of facades on achieving the thermal comfort and the study of thermal insulation by both design elements and technical elements. It also deals with the presentation of examples of office buildings, the dynamic shading elements (the subject of the research) were applied in their facades and a comparison was made between these examples. In the analytical part of the research, the building of the Central Auditing Organization was selected as an office building in Egypt to study the possibility of using dynamic shading elements in its facade.
\end{abstract}

\section{Key Words: Dynamic Shading Elements, Elevation Thermal Insulation, Thermal Comfort, Office Buildings.}

$$
\begin{aligned}
& \text { تأثثر استخدام التظليل الايناميكي على الأداء الحراري داخل المباني الإدارية في مصر } \\
& \text { هدير ماجد محمد } \\
& \text { طالبة بالدر اسات العليا، كلية الهندسة، جامعة عين شمس }
\end{aligned}
$$

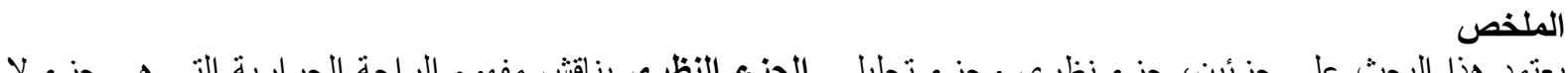

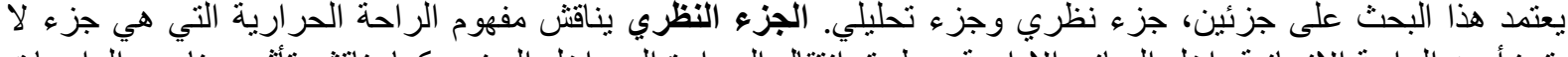

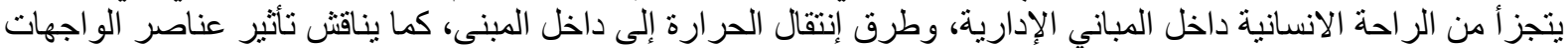

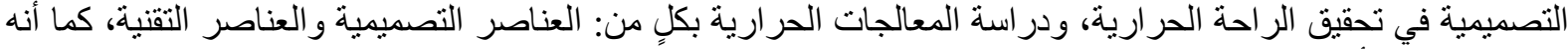

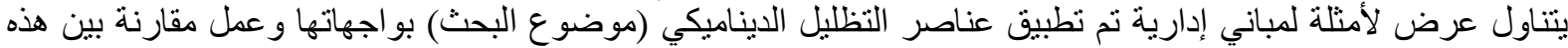

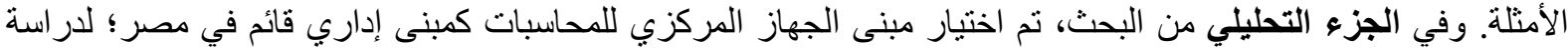

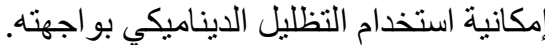

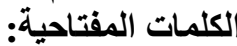
عناصر التظليل الديناميكية، المعالجات الحر ارية للواجهات، الراحة الحرارية، المباني الإدارية.

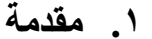

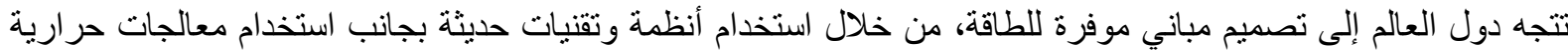

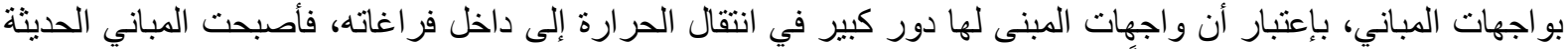

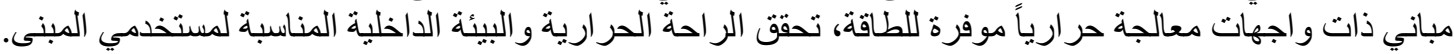

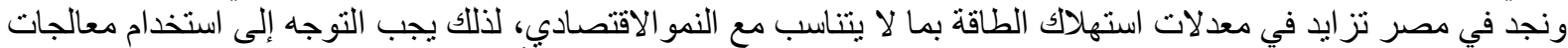
حر ارية بواجهات المباني بمختلف أنواعها كي تعمل على تخفيض الاستهلاك، ونظر ألأن نسبة المباني القائمة أكثر من المباني
} 
الجاري تنفيذها، فمن المهم دراسة إمكانية جعل هذه المباني موفرة للطاقة وتحقق الراحة الحرارية داخل فر اغاتها؛ حتى

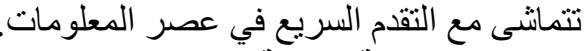

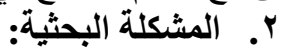

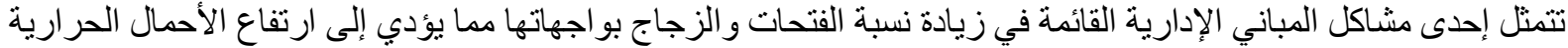

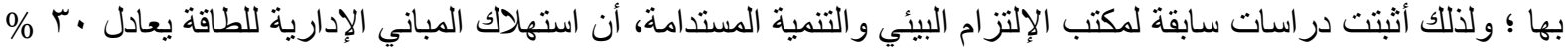

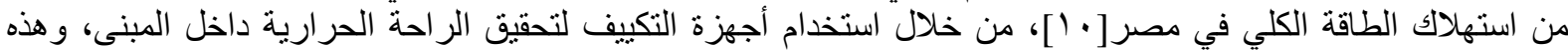

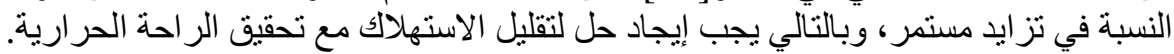

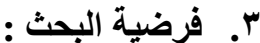

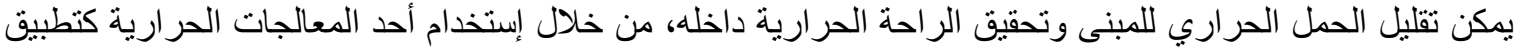

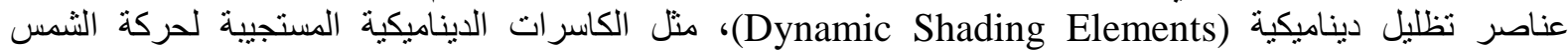

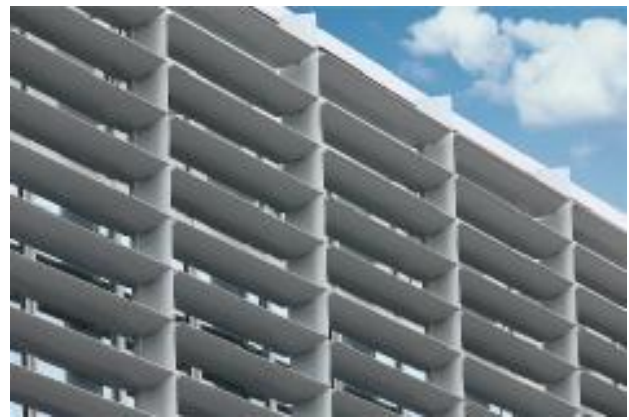

شكل (r) عناصر تظليل أفقية ميكانيكية بو اجهات مبنى إداري قائم.

تجميع معلو البحث: المباني عمل در اسة تحليلية لدور الواجهات وتأثير ها على الأداء الحراري للمبنى وتحقيق الر احة الحر ارية داخله.

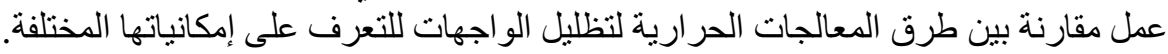

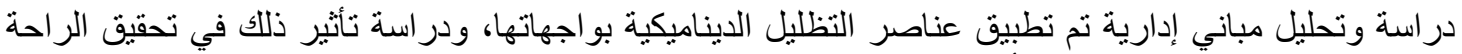

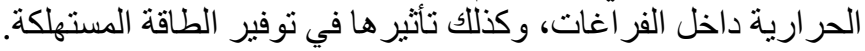

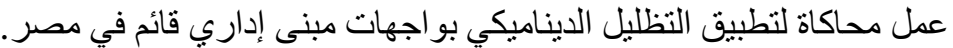

إن الوصول إلى نتائج فعالة من استخدام (Dynamic louvers) في مبنى إداري قائم في مصر أمر مهم، وسيعد أحد الحلول

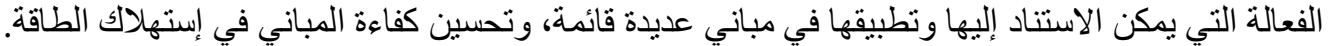

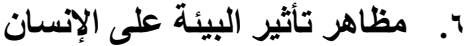

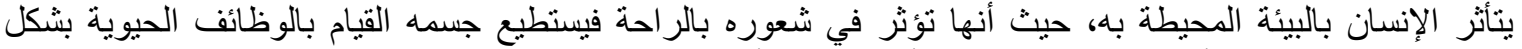
طبيعي، وتؤثر على مستوى أدائه سواء مستويات الأداء الذهنية أو العضلية، كما تؤثر على حلى حالته الصحية و على قدرته على على

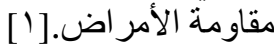

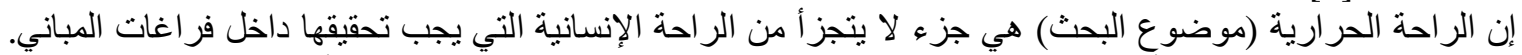

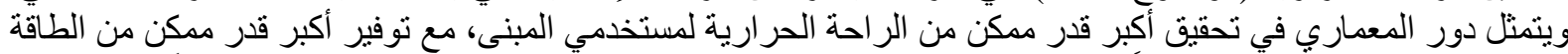

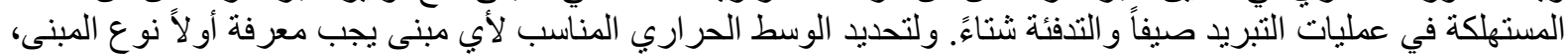

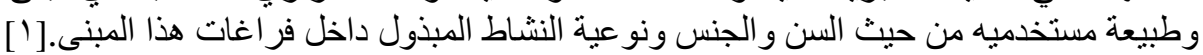




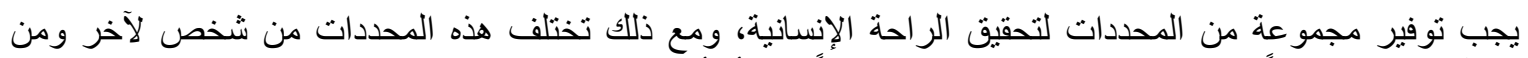

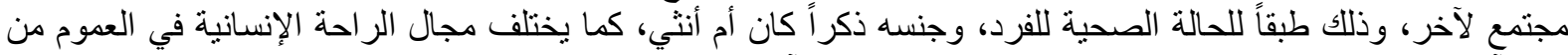
فرد لآخر على مدار العام، وتشمل محددات الر احة الإنسانية الآتي (شكل آثان):

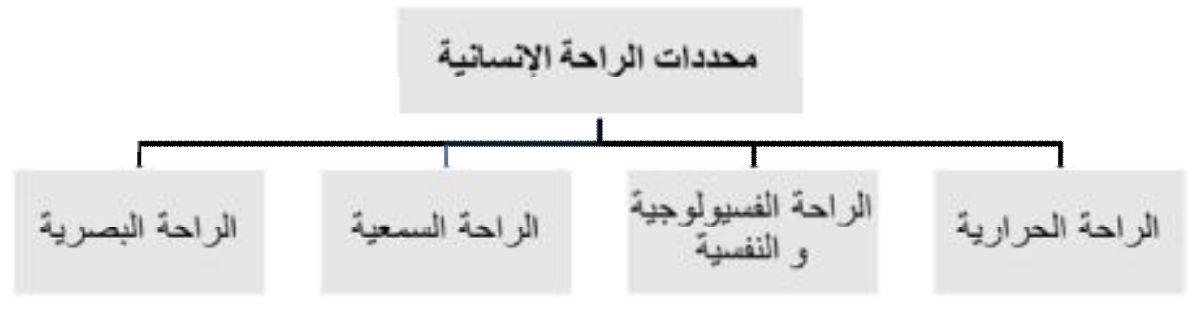

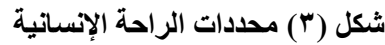

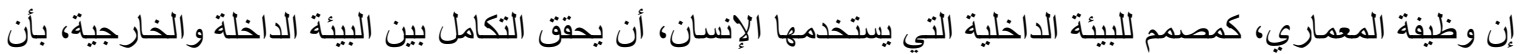

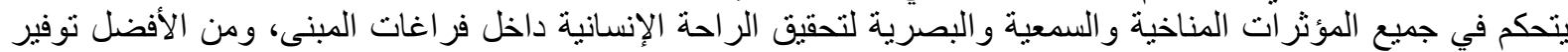

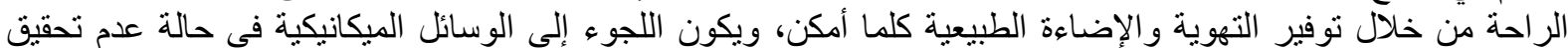

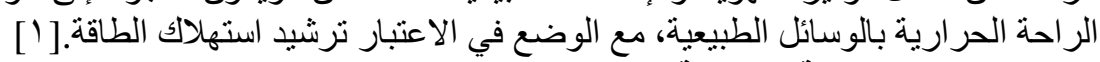

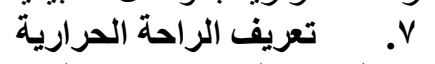

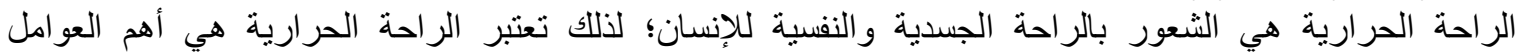

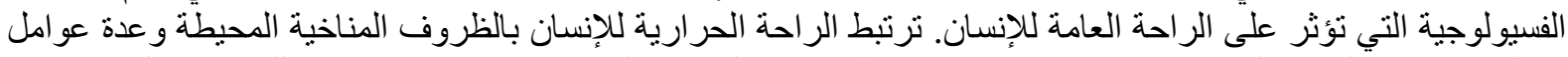

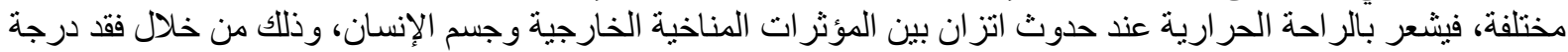

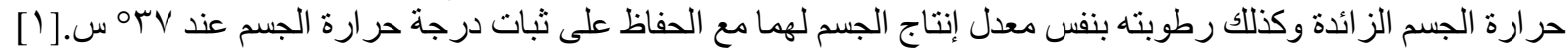

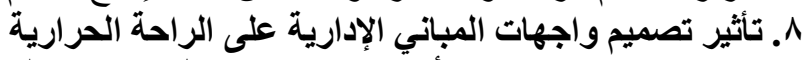

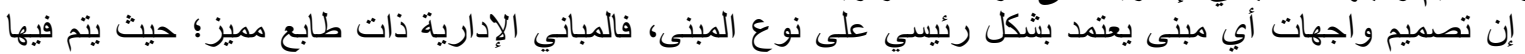

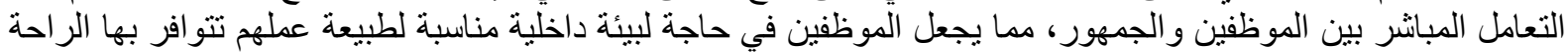

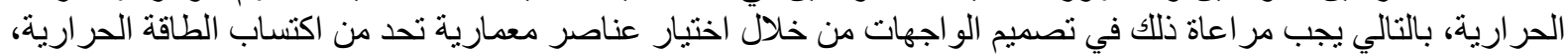
ونفاذ الأشعة الثنمسية إلى داخل المبنى، من ثم الوصول إلى الر احة الحر ارية مع خفض استهلاك المبنى للطاقة المستخدمة في الكي

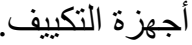

9. العناصر التصميمية التي تؤثر في المعالجات الحرارية للواجهات

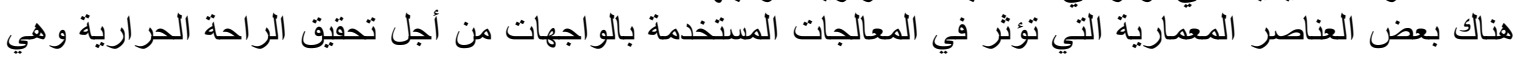

•

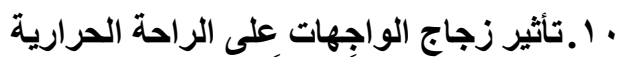

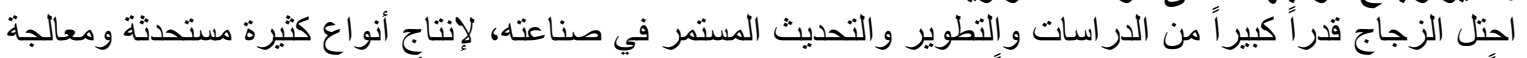

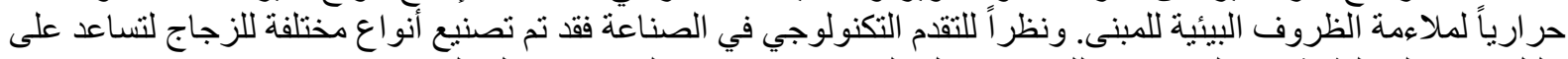

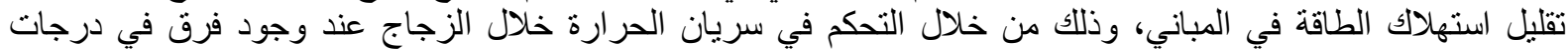

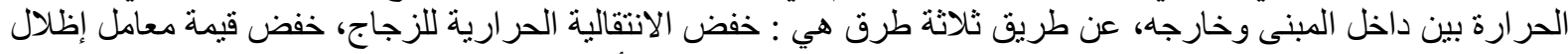

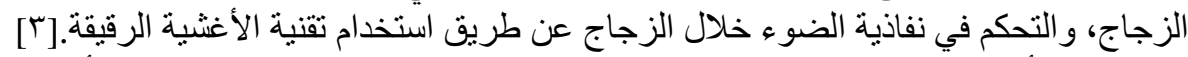

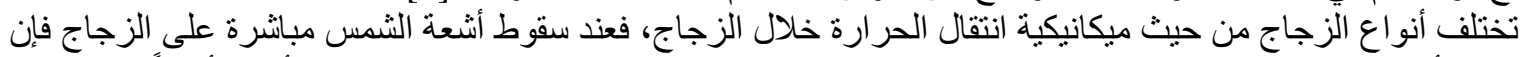

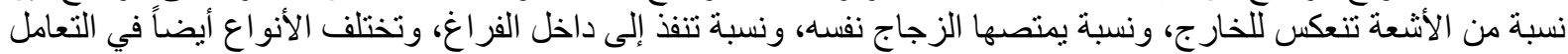

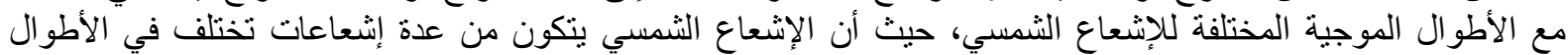

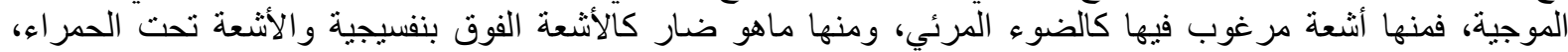


وبالتالي أفضل نوع زجاج هو الذي يسمح بدخول الضوء المرئي ويمنع دخول الأشعة فوق البنفسيجية والأشعة تحت الحمراء،

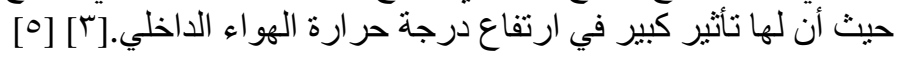

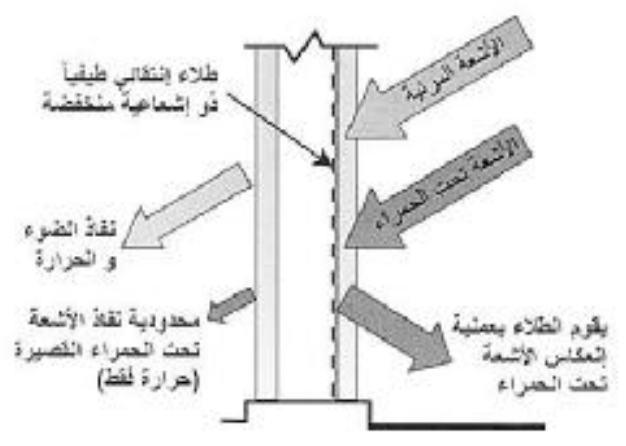

شكل ( ) سلوك الإشعاع الشمسي خلال لوح زجاجي

هناك أنواع مختلفة لزجاج الواجهات منها:[ب]

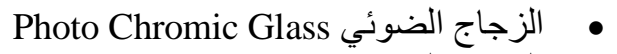

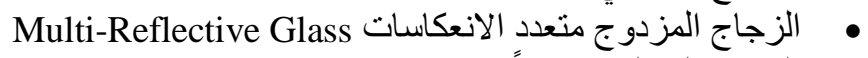

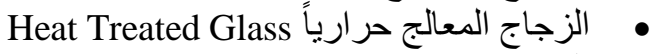

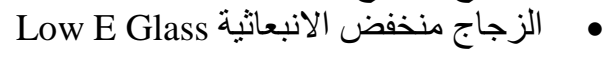

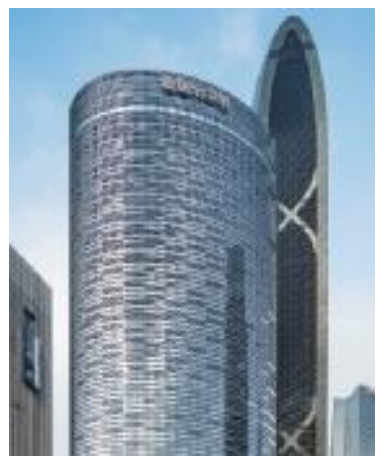

شكل (†) واجهة مبنى إداري في الصين من الزجاج الضوئي

[7]

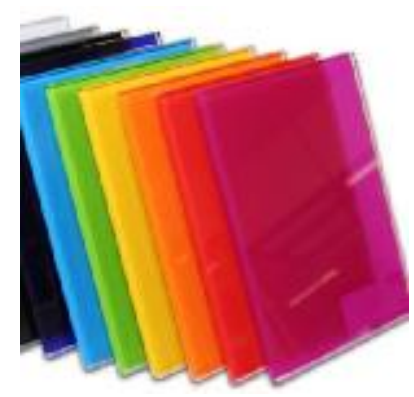

شكل (^) ألوان الزجاج الملون المعالج حرارياً [^]

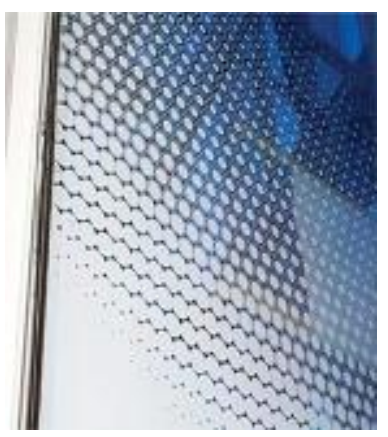

شكل (•) نموذج لثكل الزجاج الضوئي [־]

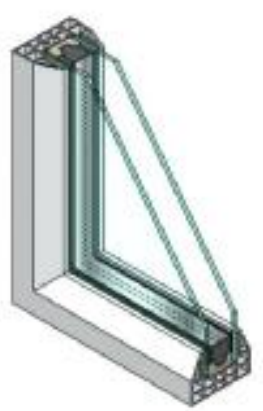

[V] قطاع في وحدة زجاج متعدد الانعكاسات (V) ش 
11 11

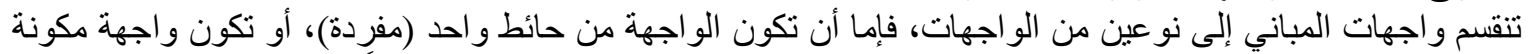

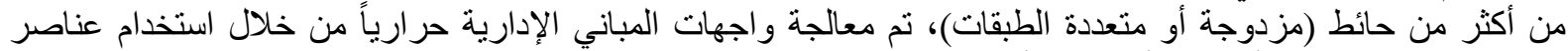

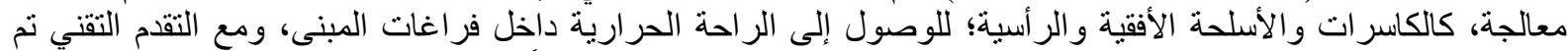

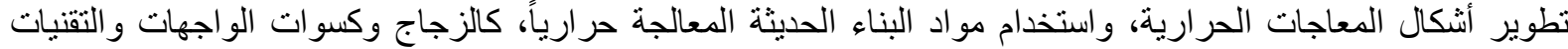

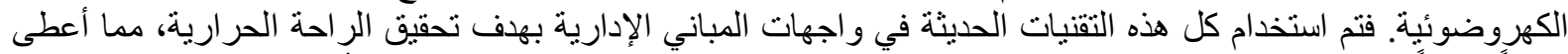

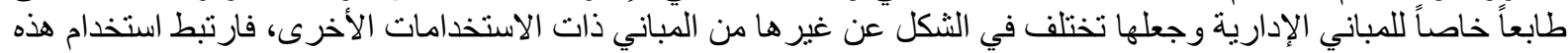

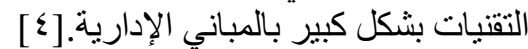

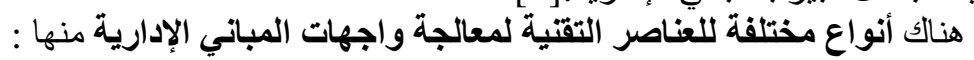

تكسيات الو اجهات المعالجة حر ارياً

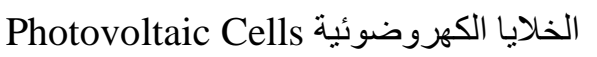

Solar Filters المرشحات الثمسية الثمبية

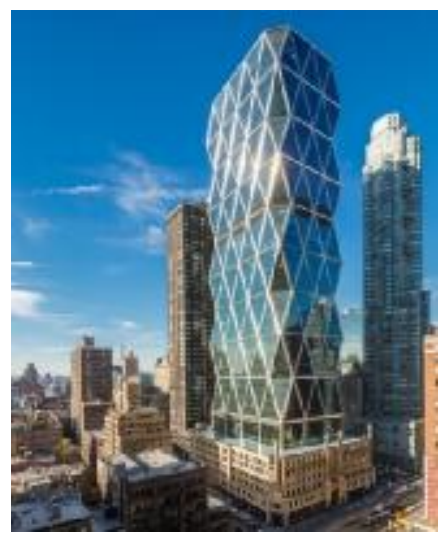

Hearst Tower شكل ( • 1 ) واجهة كهروضوئية بمبنى

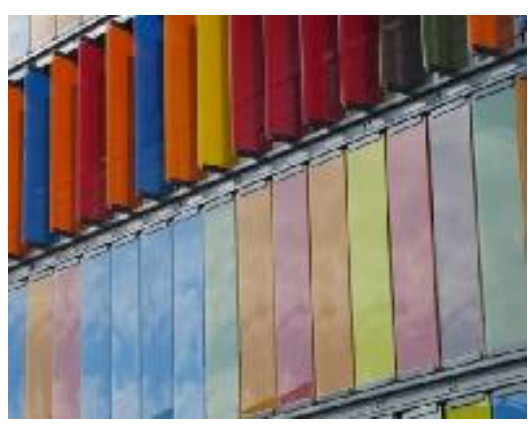

شكل (r ا ) الكاسر ات المتحركة الخارجية

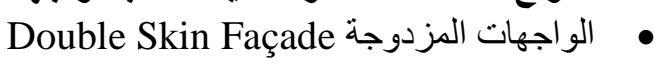

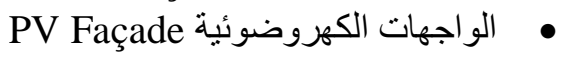

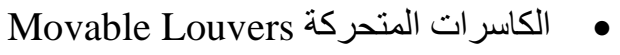

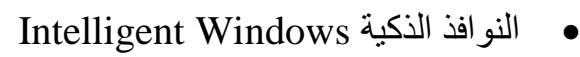

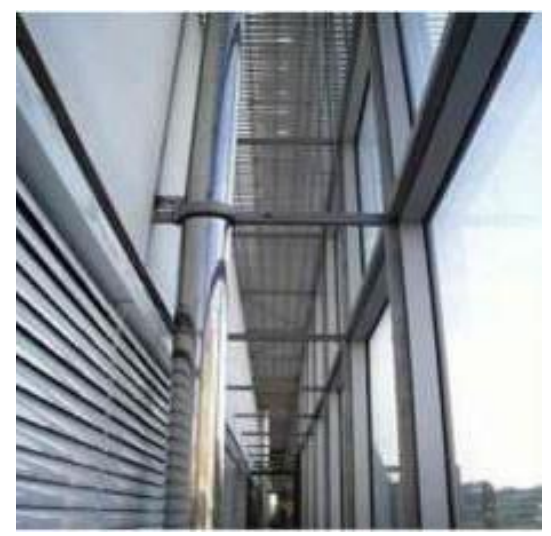

شكل (9) واجهة مزدوجة متعدة الأدوار

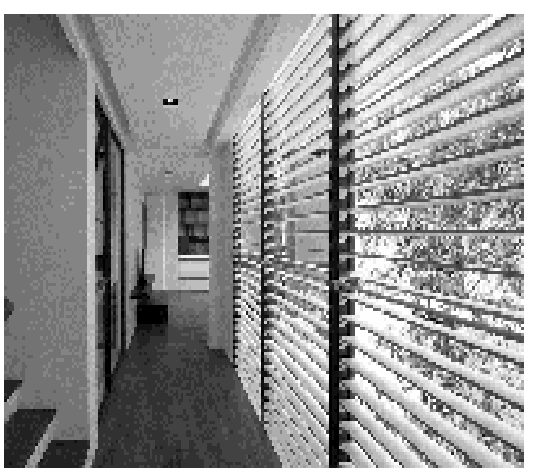

شكل (11) الكاسر ات المتحركة الداخلية 


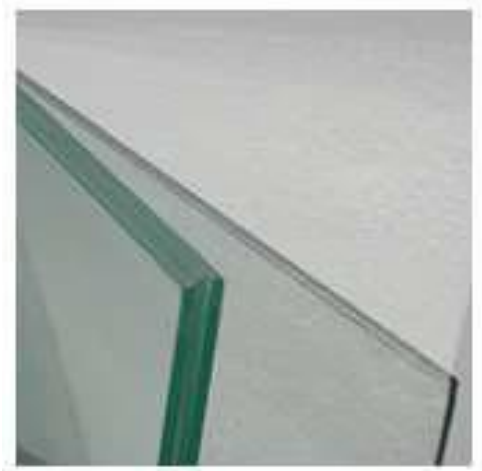

شكل (ع ( ) مرشحات ضوئية. ألو اح من الأكريليك

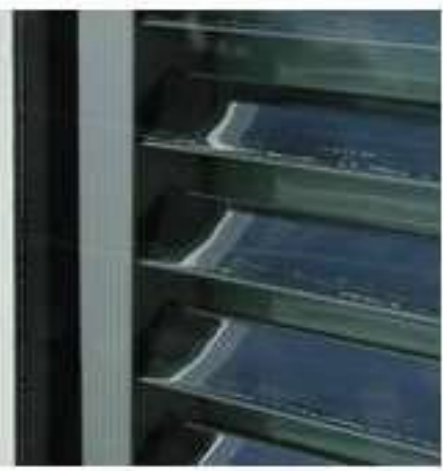

شكل (T) ا ) مرشحات ضوئية شر ائح معدنية

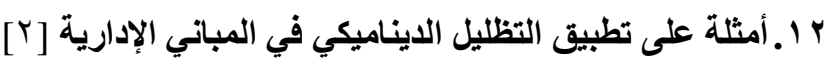

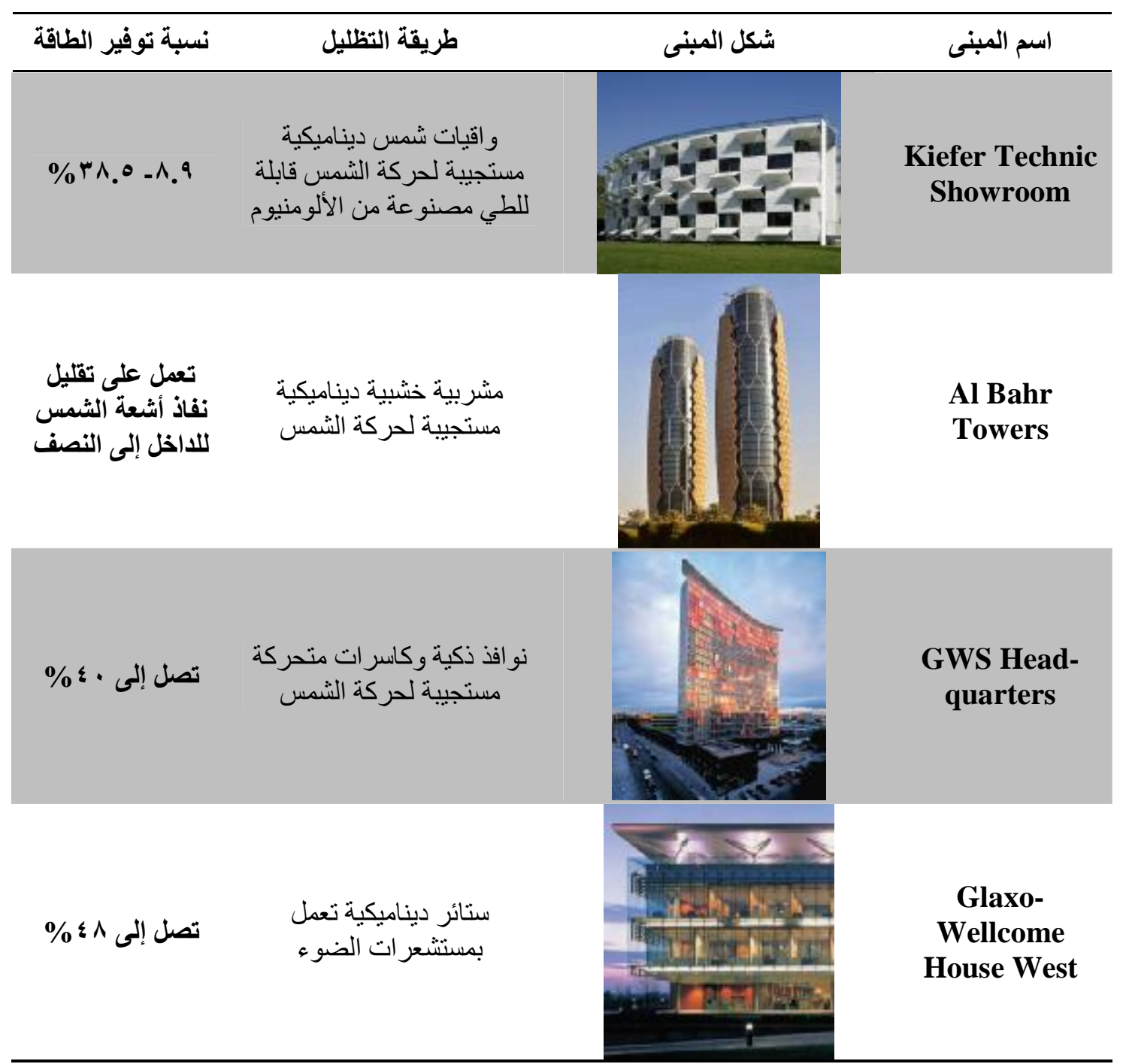




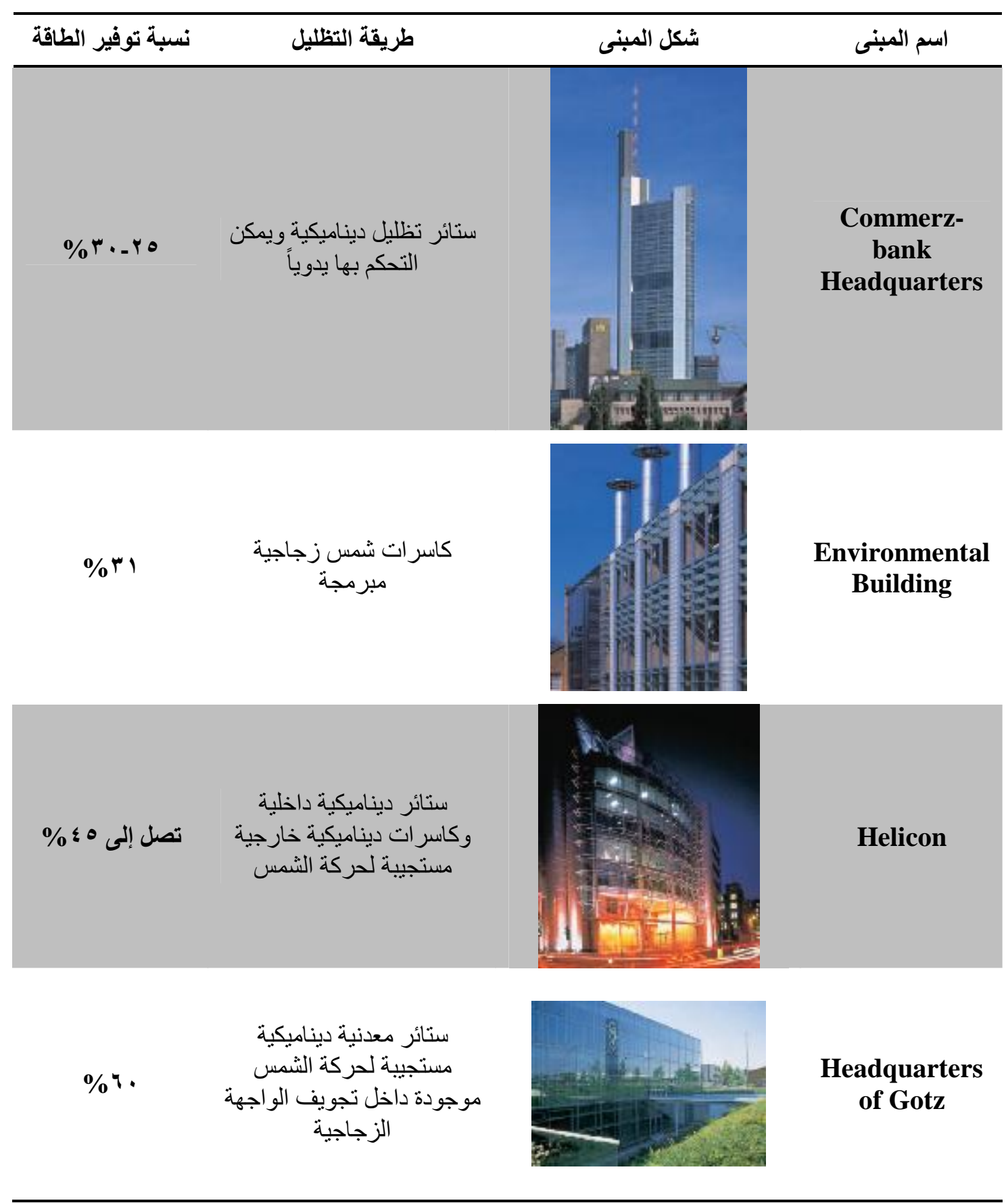




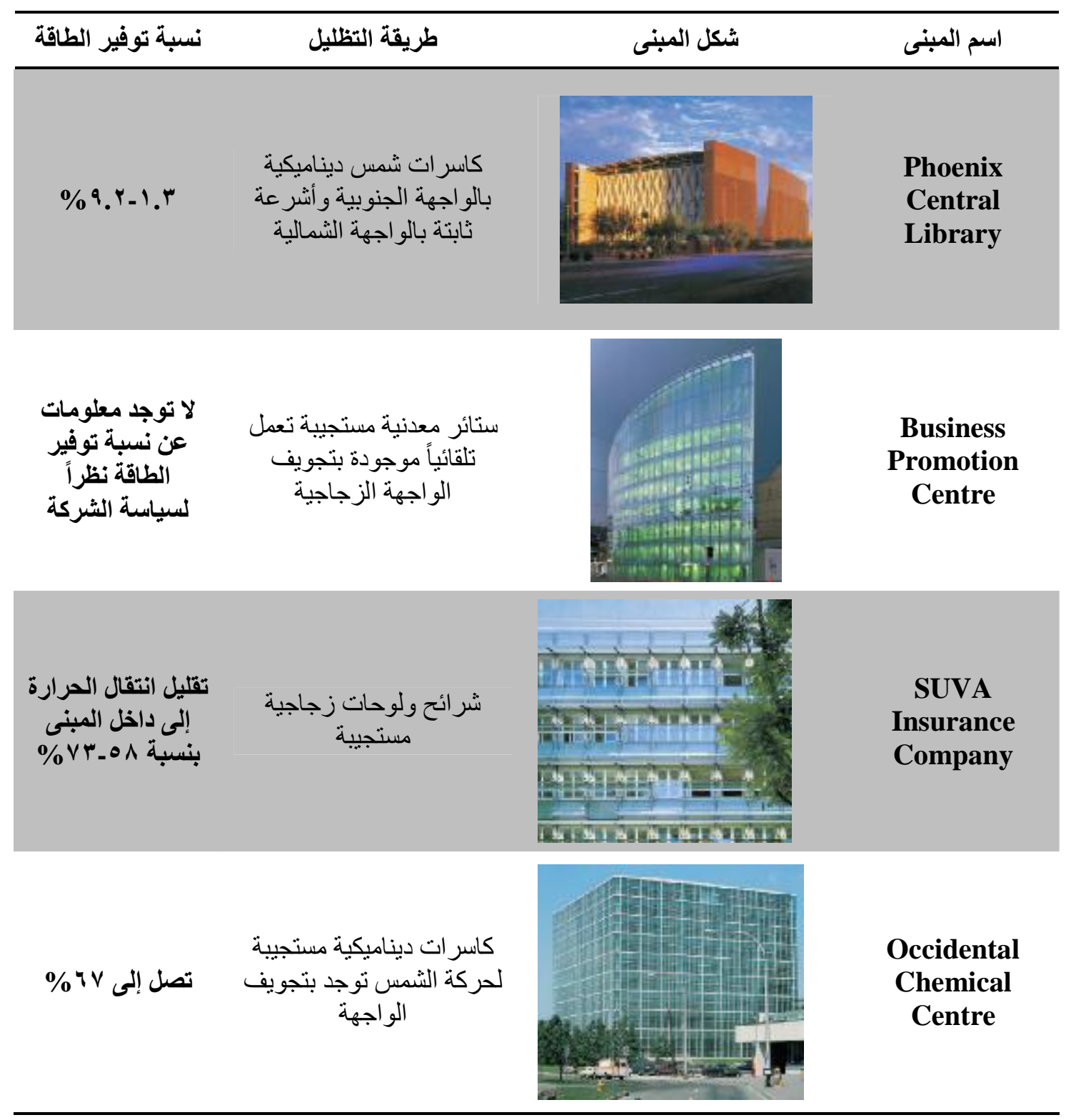

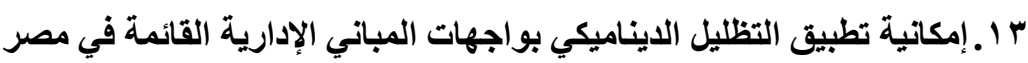

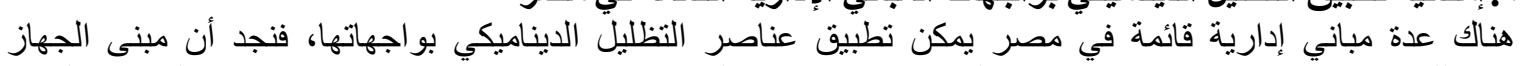

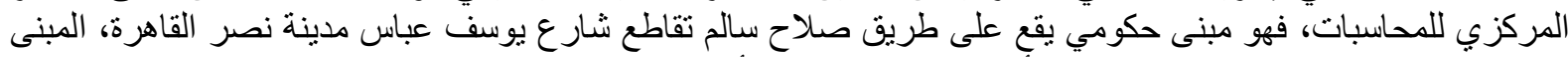

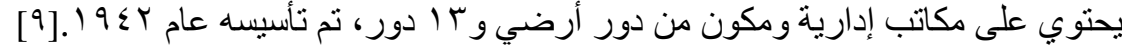




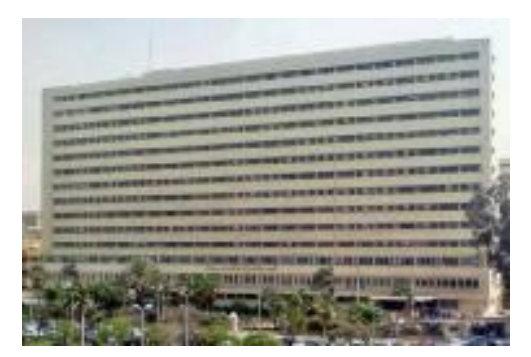

شكل (0 1 ) واجهة مبنى الجهاز المركزي للمحاسباتصورة قديمة

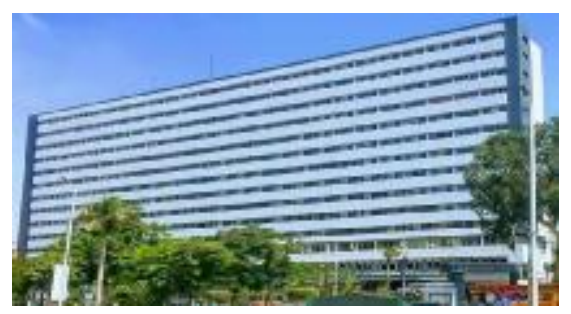

شكل (1 1 ) واجهة مبنى الجهاز المركزي للمحاسبات. صورة حليثة

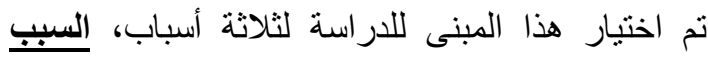

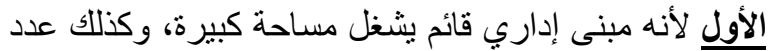
كبير من الأدوار، ويبلغ المجموع الكلى لعدد العاملين

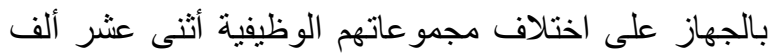
موظف، حيث يحتوي على ثناثة وأربعون إدارة مركزية وست وثناثثن إدارة مر اقبة حسابات، مما يزيد من استهلاكك

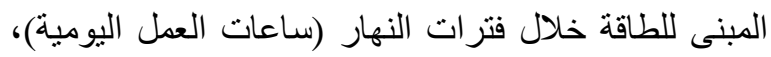
والسبب الثاني أنه يحقق أسس ومعايير تصميم المباني الإدارية، حيث يعتمد تصميم الواجهة على شبكة تصميمية ثابتة فهي واجهة تقليدية، وهي واجهة شمالية غربية،

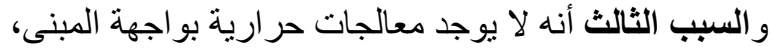
حيث تعتمد فر اغات المبنى الداخلية على الستائر التي يتم فتحها و غلقها بدوياً.

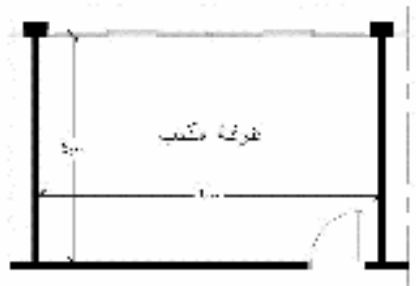

شكل (IV) مسقط أفقي لغرفة إداريةبتصرف الباحث
قد تم إختيار غرفة إدارية تقع على الواجهة الرئيسية للمبنى، وهي

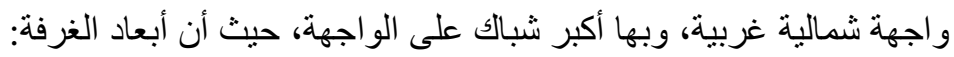

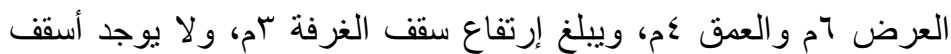

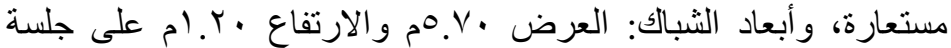

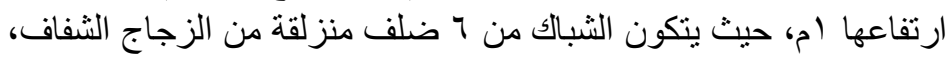
ويوجد مكان لوضع ستارة معدنية داخلية، ولكن لا توجد ستارة مستخدمة.

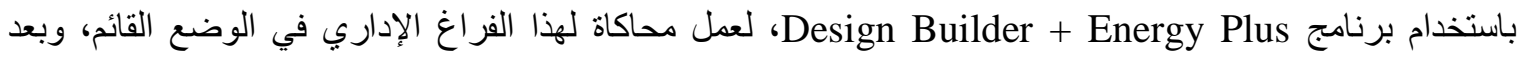

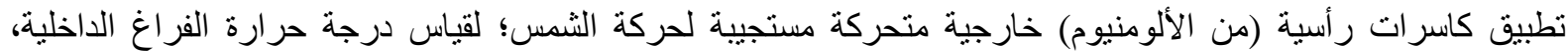

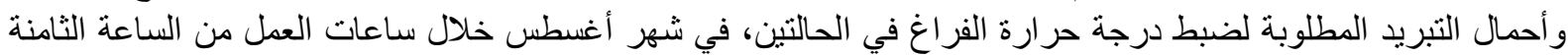
صباحاً حنى الساعة الثالثة مساءاً، فكانت النتائج كالتالي:

الوضع القائم: أعلى درجة حرارة داخل الفراغ خلال ساعات العمل هي •؟ مس، و أعلى نسبة اكتساب الحرارة خلال النافذة هي 0 الك.و ات/الساعة. 


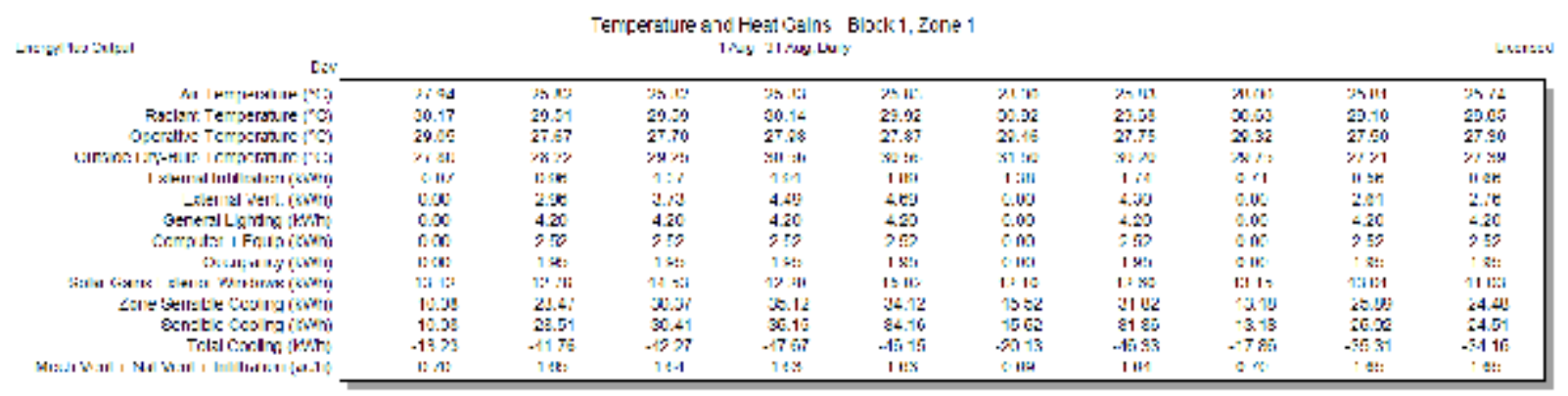

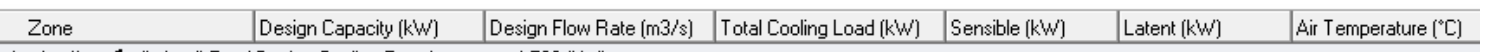
Total Design Cooling Requirement = 4.520 (kW/)

- Block 1 Total Design Cooling Requirement $=4.520(\mathrm{~kW})$

شكل (1 ا ) قياسات درجات الحرارة للفراغ والاكتساب الحراري وأحمال التبريد بالوضع القائم

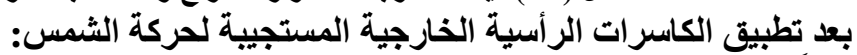

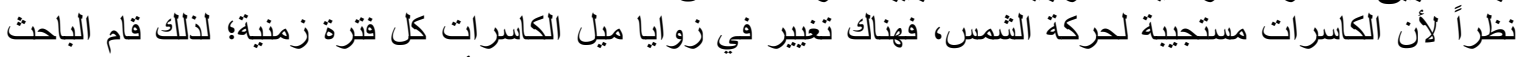

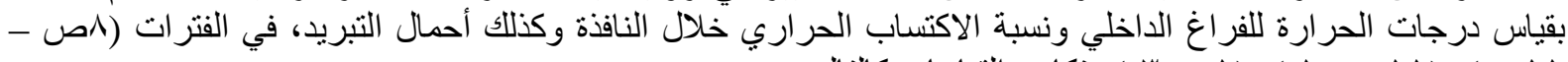

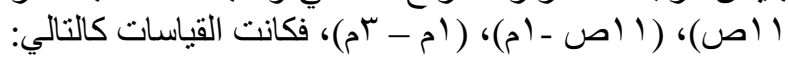

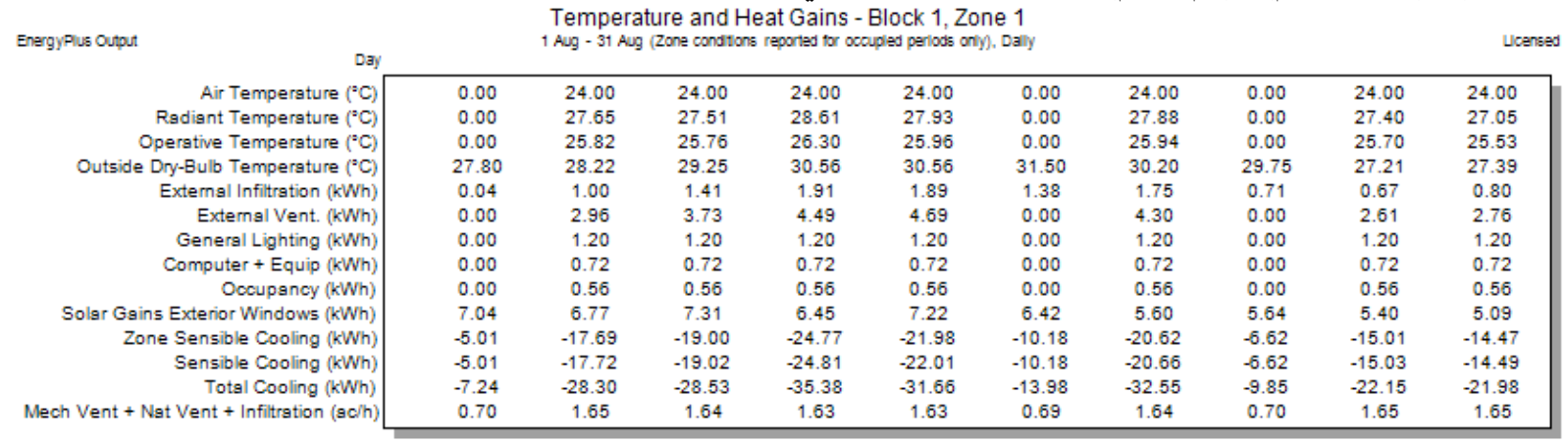

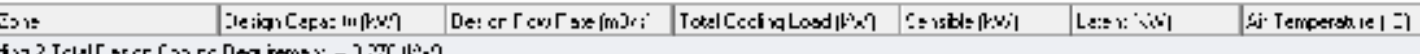

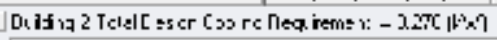

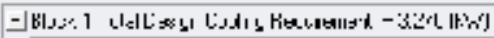
$327 \quad 027$ $\therefore 9$ r 率

شكل (9 1) قياسات درجات الحرارة للقراغ والاكتساب الحراري وأحمال التبريد - من ^ص إلى ا اص Temperature and Heat Gains - Block 1, Zone 1
Energypius Output
1 Aug - 31 Aug (Zone condtons reported for ocouples periods only), Dally

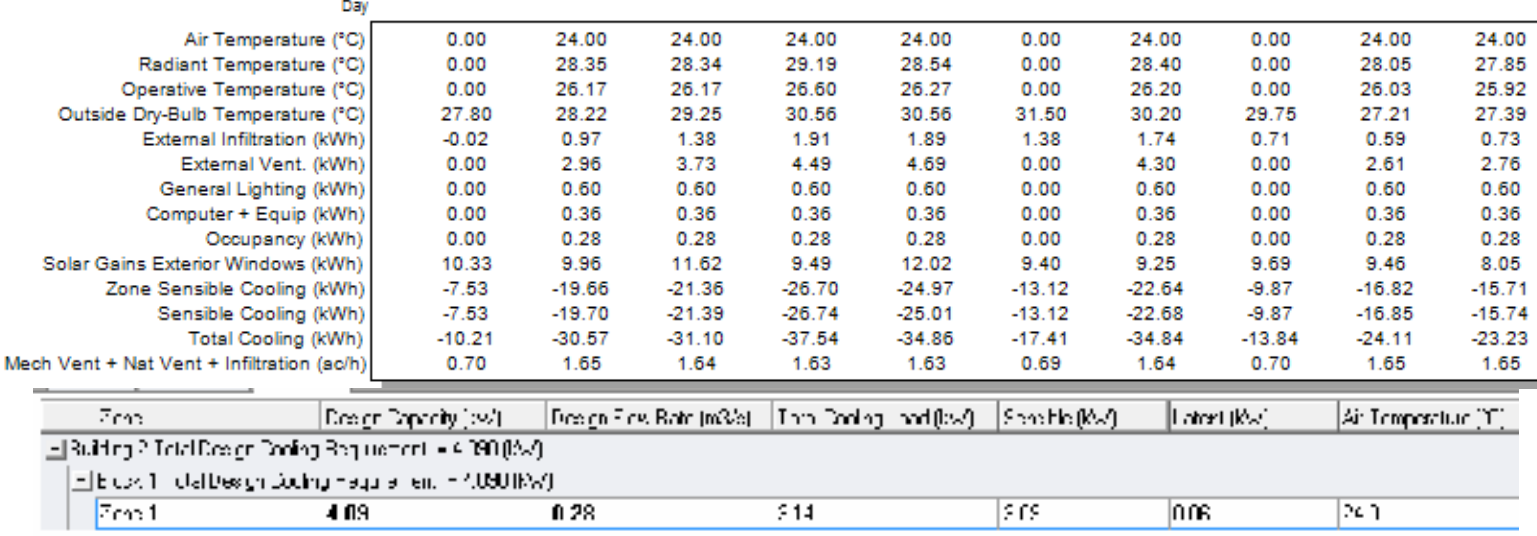

شكل (· ץ) قياسات درجات الحرارة للفراغ والاكتساب الحراري وأحمال التبريد ـ من الص إلى ام 


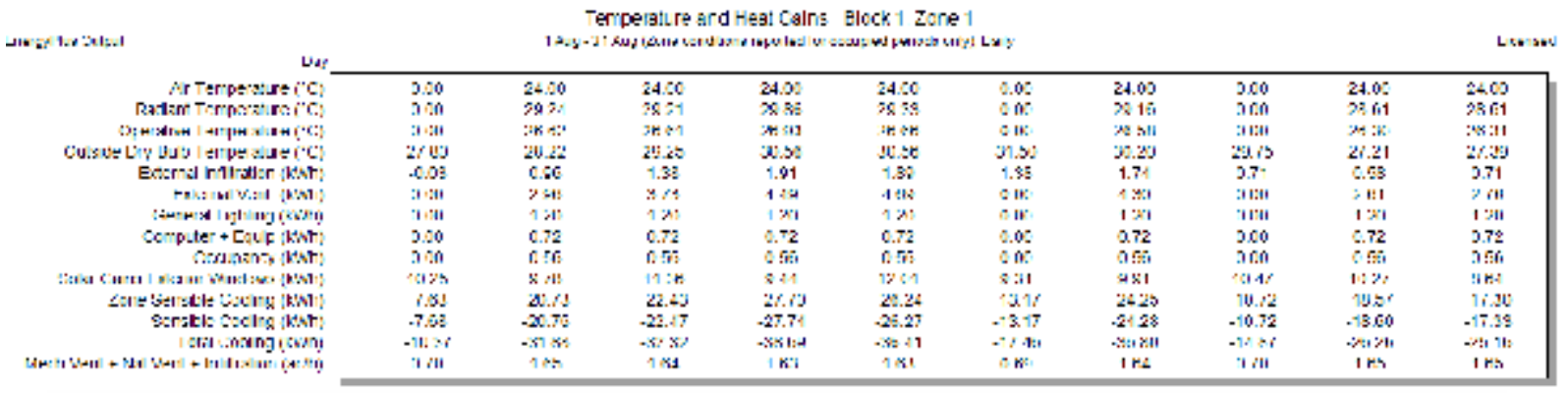

\begin{tabular}{|c|c|c|c|c|c|c|}
\hline Zcre & Detcr Eascibs iv & 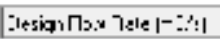 & Ts:s Codre Lest is: & 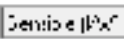 & -stetkik:k? & $\Delta \dot{r}^{-}:-$relalJ': " $\mathrm{C}$ \\
\hline \multicolumn{7}{|c|}{ 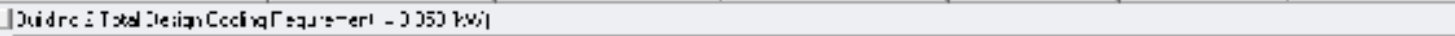 } \\
\hline \multicolumn{7}{|c|}{ 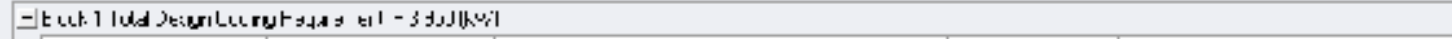 } \\
\hline Frre 1 & 395 & n 77 & frd & 273 & inf & 240 \\
\hline
\end{tabular}

شكل ( ا Y) قياسات درجات الحرارة للفراغ والاكتساب الحراري وأحمال التبريد - من ام إلى بّم

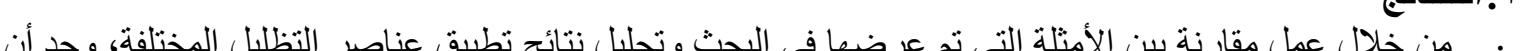

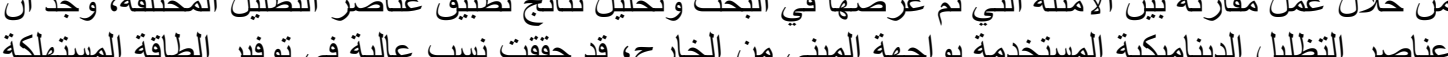

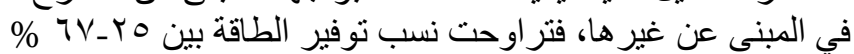

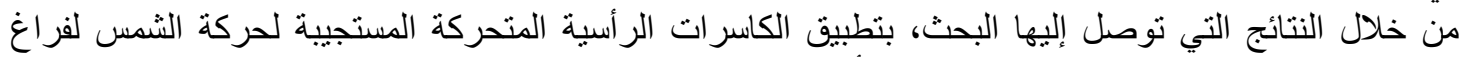

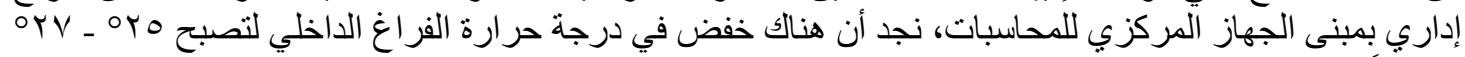

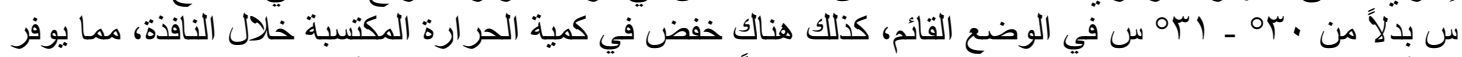

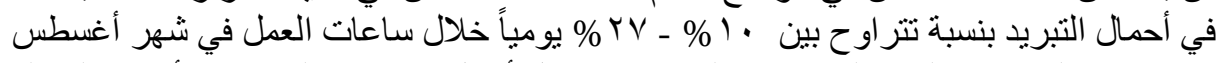

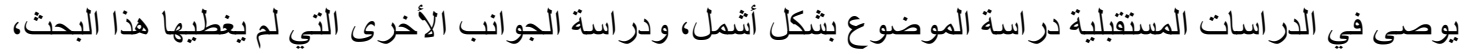

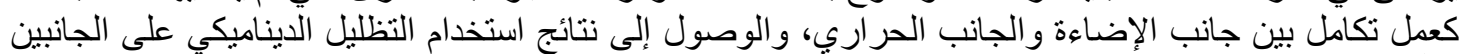

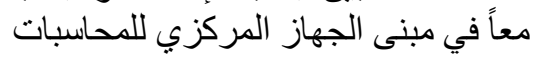
المراجع

1. Fabbri, K. (2015), “Indoor Thermal Comfort Perception”, Italy: Springer International Publishing.

2. W. Michael, Jude Harris (2012), "Intelligent Skins", London, A division of Reed Educational and Professional Publishing Ltd.

3. Compagano, A. (2008), "Intelligent Glass Façade “, Berlin, Brik Hauser Publisher for Architecture.

4. Poirazis, H. (2004), "Double Skin Façade for Office Building ", Literature Review, Lund Institute of Technology, Swedish University.

5. Smith, G., S., Dligatch, and M. Ng. (2008), "Optimizing Daylighting and Thermal Performance of Windows with Angular Selectivity", Sydney: Department of Applied Physics, University of Technology.

المواقع الإلكترونية:

6. https://inhabitat.com/soms-elliptical-agile-corporation-headquarters-has-strategicallyplaced-fins-to-mitigate-solar-gain/

7. http://www.plasto.ee

8. http://installation.showerdoorsnyc.net/2016/03/color-glass-laminated.html

9. http://www.asa.gov.eg/page.aspx?id=1, Last accessed 03-12-2018.

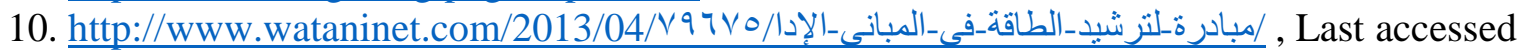
30-01-2019. 